DOI: $10.20472 / E S .2016 .5 .4 .004$

\title{
PUBLIC DEBT AND ECONOMIC GROWTH IN UZAWA'S TWO-SECTOR MODEL WITH PUBLIC GOODS
}

\section{WEI-BIN ZHANG}

\begin{abstract}
:
This paper studies public debt dynamics in a neoclassical growth model. The economy consists of one capital, one service and one public sector. The model is a synthesis of Solow's growth, Uzawa's two-sector, and Diamond's debt models. The public sector supplies services which directly affect productivity of the two sectors and welfare of the population. The government finances public expenditure by taxing the outputs, consumption, wealth income, and wage households. The study focuses on the effects of changes in government's expenditure, the public sector's productivity, and different taxes on the dynamics of public debt and economic growth. Comparative dynamic analysis examines the effects of changes in preference and polices.
\end{abstract}

\section{Keywords:}

public debt, tax rates, public good, growth

JEL Classification: $041, \mathrm{H} 41, \mathrm{H} 63$

\section{Authors:}

WEI-BIN ZHANG, Ritsumeikan Asia Pacific University, Japan, Email: wbz1@apu.ac.jp

\section{Citation:}

WEI-BIN ZHANG (2016). Public Debt and Economic Growth in Uzawa's Two-Sector Model with Public Goods. International Journal of Economic Sciences, Vol. V(4), pp. 51-72., 10.20472/ES.2016.5.4.004

Acknowledgements: The author is grateful to the constructive comments of the two anonymous referees. The author also thank Japan Society for the Promotion of Science for the financial support from the Grants-in-Aid for Scientific Research (C), Project No. 25380246. 


\section{Introduction}

Many models have been developed to study relations between national debts and growth. The emergence of huge public debts in the last three decades in different economies has stimulated theoretical as well as empirical analyses of national debts in the literature of economics. The purpose of this study is to address issues related to public debt in the neoclassical growth framework.

The main features of economic growth are based on the neoclassical growth theory. The neoclassical theory is based on the pioneering works of Solow (1956) and Swan (1956). In the stand neoclassical growth model, capital and labor are substitutes for one another with the result that the long-run growth path of the economy is one of full employment. The three factors, capital, labor and technology, are the key determinants of economic growth. Although the earlier models of the theory treat labor and technology as exogenous variables, many efforts have been made to relax the traditional assumptions. The Solow model shows that the razor-edge growth path of the Domar model is primarily a result of the particular production function assumption adopted therein and that the need for delicate balancing may not arise when the production function is taken on a different type. The Solow model has been extended and generalized in numerous directions (Burmeister and Dobell, 1970; Zhang, 2005). This paper follows the traditional two-sector economy initially proposed by Uzawa (1961). The Uzawa model extends the Solow model by a breakdown of the productive system into two sectors using capital and labor, one of which produces capital goods, the other consumption goods (Solow, 1962). This paper introduces an alternative approach to consumer decision to examine structural change within Uzawa's two-sector economy.

This study is concerned with issues related to the role of fiscal policies on economic growth. We are concerned with dynamic interdependence between economic growth and public investment. Some recent endogenous growth models have emphasized the role of productive fiscal policy as a determinant of persistent economic growth (Barro, 1990; Turnovsky, 2000, 2004; Glomm and Ravikumar, 1997; Gómez, 2008; and Park, 2009). As in Hochman (1981) and Wijkander (1984), this paper is concerned with provision of public goods. We assume that only the government is responsible for the provision of public goods. The government chooses the values of a set of control measures according to some predetermined rules. The government provides public goods, minimizing the cost of public goods provision under these rules. The set of control measures at the government's disposal includes the total expenditures and tax rates on the industrial sector's output, the service sector's output, the wage income, the consumption and the interest income. The modeling of this study is also influenced by Lin (2000). This study is different from Lin's model in that the Lin's model is developed in the discrete Uzawa-Lucas two-sector model, while this model is a continuous Uzawa's two-sector growth model. In Lin's model, the government expenditure is spent on education, while in this study the public expenditure is spent on providing public services which are used by the two production sectors and the household. In Lin's model, there is only one lump sum tax on the household, while in this study the government may tax on the household's wage 
income, wealth income, consumption, as well as on the two production sectors' outputs. Lin's examination is focused on the effects of changes in some parameters on the steady state; while this study is focused on effects of changes in some parameters on the dynamic paths of the economic system as well as on the equilibrium point. Almost of all the recent theoretical literature of dynamic interactions between economic growth and public debts use either the Ramsey framework in continuous time (Cohen and Sachs, 1986; Blanchard and Fischer, 1989; Barro et al. 1995; Semmler and Sieveking, 2000; Guo and Harrison, 2004; and Giannitsarou, 2007) or the OLG modeling framework in discrete time (Diamond, 1965; Farmer, 1986; Turnovsky and Sen, 1991; Azariadis, 1993; de la Croix and Michel, 2002; and Chalk, 2000). Different from the traditional approaches to household decision, this study uses Zhang's approach to household decision to re-examine the debt issues addressed by Diamond (1965). Zhang proposed the alternative approach in the early 1990s (Zhang, 1993). The implications of this approach are similar to those in the Keynesian consumption function and models based on the permanent income hypothesis, which are empirically much more valid than the approaches in the Solow model or the in Ramsey model. The approach is discussed at length by Zhang $(2005,2008)$. Zhang (2005) has also examined the relations between his approach and the Solow growth theory, the Ramsey growth theory, the permanent income hypothesis, and the Keynesian consumption function in details. It can be shown that the behavior generated by the traditional approaches can also be observed in Zhang's approach by specifying certain patterns of preference changes. As it assumes a fixed proportion of disposable income (which is the current income in Zhang's approach) is saved, the Solow model does not take account of how changes in wealth affect saving behavior. Although it can be generalized to take account of the possible impact of wealth on saving behavior, the traditional Keynesian consumption function lacks a rational micro foundation. The approach becomes less effective when one has to deal with multiple goods and saving in a consistent manner. The Ramsey approach is based on the assumption that the utility is additional for the same person over the person's life time. There extensive studies on the limitations of this formation. A comprehensive survey of the literature is referred to Frederick et al. (2002). Zhang proposes an alternative approach to the household behavior by taking account of the valid points and overcoming the shortcomings in the traditional approaches. The rest paper is organized as follows. Section 2 defines the basic model. Section 3 shows how we solve the dynamics and simulates the model. Section 4 examines effects of changes in some parameters on the economic system over time. Section 5 concludes the study. The appendix proves the main results in Section 3.

\section{The growth model with government debt}

The model is based on the basic features of three well-known models, the growth model of Solow (1956), the two-sector growth model of Uzawa (1961), and the growth model with public debt of Diamond (1965). The household decision is based on Zhang's approach (Zhang, 1993). Following the traditional two-sector growth model, we consider an economy 
which produces capital good and consumption good. We extend the two-sector growth model by introducing public sector. The public sector uses capital and labor as inputs and supplies public services which are freely available to consumers and producers. The public sector is financially by the government which taxes the household and the two production sectors. The price of the industrial good is unity. Capital depreciates at a constant exponential rate, $\delta_{k}$, which is independent of the manner of use. Technologies of the production sectors are characterized of constant returns to scale. All markets are perfectly competitive and capital and labor are completely mobile among the sectors. All private assets are held by the households either as capital or in the form of government debt. We assume that labor is homogeneous and is fixed. We use subscript index, $i, s$, and $p$, to denote respectively the industrial and service sectors. Let $\tau_{i}, \tau_{s}, \tau_{w}$, and $\tau_{k}$, stand for, respectively, the fixed tax rates on the industrial output, the service output, the wage income, and the interest income. We introduce $\bar{\tau}_{x} \equiv 1-\tau_{x}$, where $x=i, s, w, k$. Let $K_{j}(t)$ and $N_{j}(t)$ stand for the capital stocks and labor force employed by sector $j, j=i, s, p$, at time $t$. We use $F_{j}(t)$ to represent the output level of sector $j$.

\section{Industrial sector}

The production function of the industrial sector is given by

$$
F_{i}(t)=A_{i} F_{p}^{\theta_{i}}(t) K_{i}^{\alpha_{i}}(t) N_{i}^{\beta_{i}}(t), \alpha_{i}, \beta_{i}>0, \alpha_{i}+\beta_{i}=1
$$

where $\alpha_{i}$, and $\beta_{i}$ are parameters. Markets are competitive; thus labor and capital earn their marginal products, and firms earn zero profits. We interpret the variables as public goods such as physical and institutional infrastructures (Zhang, 2009, 2011). The aggregate public goods $F_{p}(t)$ is supplied by the government and is taken as given by the firms. Despite increasing social returns to scale, the function allows to maintain the assumption of perfect competition in the goods market since the technology exhibits constant returns to scale for any given level of public goods, which firms cannot control. We use $w(t)$ and $r(t)$ to stand for the wage rate and rate of interest. The profit is

$$
\pi_{i}(t)=\left(1-\tau_{i}\right) F_{i}(t)-\left(r(t)+\delta_{k}\right) r(t)-w(t) N_{i}(t)
$$

The marginal conditions for maximizing the profit are

$$
r_{\delta}(t)=\alpha_{i} \bar{\tau}_{i} A_{i} F_{p}^{\theta_{i}}(t) k_{i}^{-\beta_{i}}(t), w(t)=\beta_{i} \bar{\tau}_{i} A_{i} F_{p}^{\theta_{i}}(t) k_{i}^{\alpha_{i}}(t),
$$


where $k_{i}(t) \equiv K_{i}(t) / N_{i}(t)$, and $r_{\delta}(t) \equiv r(t)+\delta_{k}$.

\section{Service sector}

The production function of the service sector is

$$
F_{s}(t)=A_{s} F_{p}^{\theta_{s}}(t) K_{s}^{\alpha_{s}}(t) N_{s}^{\beta_{s}}(t), \alpha_{s}, \beta_{s}>0, \alpha_{s}+\beta_{s}=1,1>\theta_{s} \geq 0
$$

where $\alpha_{s}$ and $\beta_{s}$ are parameters. We use $p(t)$ to stand for the price of service. The profit is

$$
\pi_{s}(t)=\left(1-\tau_{s}\right) p(t) F_{s}(t)-\left(r(t)+\delta_{k}\right) r(t)-w(t) N_{s}(t)
$$

The marginal conditions for the service sector are

$$
r_{\delta}(t)=\alpha_{s} \bar{\tau}_{s} A_{s} F_{p}^{\theta_{s}}(t) p(t) k_{s}^{\alpha_{s}-1}(t), w(t)=\beta_{s} \bar{\tau}_{s} A_{s} F_{p}^{\theta_{s}}(t) p(t) k_{s}^{\alpha_{s}}(t)
$$

where $k_{s}(t) \equiv K_{s}(t) / N_{s}(t)$.

\section{The public sector}

We now describe the public sector. In this model, we assume that the public sector is financially supported by the government. The capital stocks and workers employed by the public sector are paid at the same rates that the private sectors pay the services of these factors. We assume that the government uses the resources effectively in the sense that the budget is used to maximize public services. The production of public services is to combine capital $K_{p}(t)$ and labor force $N_{p}(t)$ as follows

$$
F_{p}(t)=A_{p} K_{p}^{\alpha_{0 p}}(t) N_{p}^{\beta_{0 p}}(t), \alpha_{0 p}, \beta_{0 p}, A_{p}>0 .
$$


For simplicity, we assume that the total expenditure on supplying the public good $Y_{p}(t)$ is constant, i.e.

$$
Y_{p}(t)=Y_{0},
$$

where $Y_{0}$ is a positive constant. The public sector is faced with the following budget constraint

$$
w(t) N_{p}(t)+r_{\delta}(t) K_{p}(t)=Y_{p}(t)
$$

Maximization of public services under the budget constraint yields

$$
r_{\delta}(t) K_{p}(t)=\alpha_{p} Y_{p}(t), w(t) N_{p}(t)=\beta_{p} Y_{p}(t),
$$

in which

$$
\alpha_{p} \equiv \frac{\alpha_{0 p}}{\alpha_{0 p}+\beta_{0 p}}, \quad \beta_{p} \equiv \frac{\beta_{0 p}}{\alpha_{0 p}+\beta_{0 p}} .
$$

\section{The government budget}

Following Diamond (1965) and Barro (1974), we assume that the government issues an amount debt $D(t)$, which may be considered as real-valued bonds. It is supposed that asset holders regard equity and government bonds as perfect substitutes. The debt pays the amount of real interest $r(t) D(t)$. The government finances current spending by collecting taxes and issuing interest-bearing debt. Let $T_{p}(t)$ stand for the government's tax income. The dynamics of public debt is

$$
\dot{D}(t)=r(t) D(t)+Y_{p}(t)-T_{p}(t)
$$


It should be noted that if $D(t)$ is negative, then the negative private ownership of capital is less than the economy's capital. This may occur, for instance, the government purchases shares in private firms and issues zero government debt.

\section{Behavior of domestic households}

This study uses an alternative approach for modeling consumers' behavior. The implications of this approach are similar to those in the Keynesian consumption function and models based on the permanent income hypothesis, which are empirically much more valid than the approaches in the Solow model or the in Ramsey model. The approach is discussed at length by Zhang (2005). It should be noted that Zhang (2005) has also examined the relations between his approach and the Solow growth theory, the Ramsey growth theory, the permanent income hypothesis, and the Keynesian consumption function in details. It can be shown that the behavior generated by the traditional approaches can also be observed in Zhang's approach by specifying certain patterns of preference changes. First, we use $\bar{k}(t)$ and $d(t)$ to represent respectively the real wealth and government debt owned by the representative household. The current income is

$$
y(t)=\bar{\tau}_{k} r(t) \bar{k}(t)+\bar{\tau}_{w} w(t)+r(t) d(t)
$$

where $r^{*} k(t)$ is the interest payment, $w(t)$ the wage payment and $d(t)=D(t) / N$. We call $y(t)$ the current income in the sense that it comes from consumers' wages and current earnings from ownership of wealth and debt. The sum of income that consumers are using for consuming and saving are not necessarily equal to the current income because consumers can sell wealth to pay, for instance, the current consumption if the current income is not sufficient for consuming. The total value of the wealth that a consumer can sell to purchase goods and to save is equal to $\bar{k}(t)+d(t)$. The disposable income at any point of time is

$$
\hat{y}(t)=y(t)+\bar{k}(t)+d(t)
$$

The disposable income is used for saving and consumption. At time $t$ the consumer has the total amount of income equaling $\hat{y}$ to distribute between consuming and saving.

At each point in time, a consumer distributes the total available budget between the consumption of services $c_{s}(t)$, industrial goods $c_{i}(t)$, and saving $s(t)$. The budget constraint is 


$$
\left(1+\tilde{\tau}_{s}\right) p(t) c_{s}(t)+\left(1+\tilde{\tau}_{c}\right) c_{i}(t)+s(t)=\hat{y}(t)
$$

where $\tilde{\tau}_{s}$ and $\tilde{\tau}_{c}$ are respectively the tax rates on the consumption of services and industrial good. Equation (12) means that the consumption and saving exhaust the consumers' disposable personal income. We assume that utility level $U(t)$ of the household is dependent on $c_{s}(t), c_{i}(t)$ and $s(t)$ as follows

$$
U(t)=\theta F_{p}^{d_{0}}(t) c_{s}^{\gamma_{0}}(t) c_{i}^{\xi_{0}}(t) s^{\lambda_{0}}(t), d_{0}, \gamma_{0}, \xi_{0}, \lambda_{0}>0
$$

in which $\gamma_{0}, \xi_{0}$, and $\lambda_{0}$ are a typical person's elasticity of utility with regard to services, industrial goods, and saving. We call $\gamma_{0}, \xi_{0}$, and $\lambda_{0}$ to consume services, to consume industrial goods, and to hold wealth, respectively. It should be remarked that Blanchard (1983) introduces the disutility of debt in the traditional utility function. Maximizing $U(t)$ subject to (12) yields

$$
c_{s}(t)=\frac{\gamma \hat{y}(t)}{p(t)}, c_{i}(t)=\xi \hat{y}(t), s(t)=\lambda \hat{y}(t),
$$

where

$$
\gamma \equiv \frac{\rho \gamma_{0}}{1+\tilde{\tau}_{s}}, \quad \xi \equiv \frac{\rho \xi_{0}}{1+\tilde{\tau}_{c}}, \lambda \equiv \rho \lambda_{0}, \quad \rho \equiv \frac{1}{\gamma_{0}+\xi_{0}+\lambda_{0}} .
$$

The household's total wealth is given by $a(t)=\bar{k}(t)+d(t)$. According to the definition of $s(t)$, the wealth accumulation for the household is

$$
\dot{a}(t)=s(t)-a(t) .
$$

This equation states that the change in wealth equals the saving minus the dissaving.

\section{The government's tax income}

The government's tax income comes from taxing the two sectors, the ownership of wealth, and consumption. We have 


$$
T_{p}(t)=\tau_{i} F_{i}(t)+\tau_{s} p(t) F_{s}(t)+\tau_{k} r(t) \bar{k}(t) N+\tilde{\tau}_{s} p(t) c_{s}(t) N+\tilde{\tau}_{i} c_{i}(t) N
$$

where $\tau_{i} F_{i}(t)$ is the government's income from taxing the capital sector, $\tau_{s} p(t) F_{s}(t)$ is from taxing the service sector, $\tau_{k} r(t) \bar{k}(t) N$ from taxing the households' interest income, $\tilde{\tau}_{s} p(t) c_{s}(t) N$ from taxing the service consumption, and $\tilde{\tau}_{i} c_{i}(t) N$ from taxing the good consumption.

\section{Demand of and supply for services}

The equilibrium condition for services is

$$
c_{s}(t) N=F_{s}(t)
$$

\section{Full employment of capital and labor}

The total capital stocks employed by the country, $K(t)$, is employed by the three sectors. The full employment of labor and capital is represented by

$$
K_{i}(t)+K_{s}(t)+K_{p}(t)=K(t), \quad N_{i}(t)+N_{s}(t)+N_{p}(t)=N .
$$

We have thus built the dynamic growth model with national debt.

\section{The Dynamics of the Economy}

The appendix shows that the motion of the economic system is determined by two differential equations with $z(t)$ and $\bar{k}(t)$ as the variables, where $z(t) \equiv w(t) /\left(r(t)+\delta_{k}\right)$. The following lemma shows how we can determine the motion of all the variables in the dynamic system.

\section{Lemma}

The motion of $\bar{k}(t)$ and $z(t)$ is determine by determined by the following two differential equations

$$
\dot{\bar{k}}(t)=\tilde{\Psi}(z(t), \bar{k}(t))
$$




$$
\dot{z}(t)=\hat{\Psi}(z(t), \bar{k}(t)),
$$

in which $\tilde{\Psi}$ and $\hat{\Psi}$ are functions of $\bar{k}(t)$ and $z(t)$ defined in the appendix. We determine all the other variables as functions of $\bar{k}(t)$ and $z(t)$ as follows: $D(t)$ by $(\mathrm{A} 12) \rightarrow r_{\delta}(t)$ by $(\mathrm{A} 11) \rightarrow r(t)=r_{\delta}-\delta_{k} \rightarrow K_{s}(t)$ by (A9) $\rightarrow K_{i}(t)$ by (A9) $\rightarrow K_{p}(t)$ by (A8) $\rightarrow$ $k_{j}(t)=z(t) / \bar{\alpha}_{j} \rightarrow N_{j}(t)=K_{j}(t) / k_{j}(t) \rightarrow K_{i}(t)$ by $(\mathrm{A} 10) \rightarrow K_{s}(t)$ by $(\mathrm{A} 6) \rightarrow$ $N_{j}(t)=K_{j}(t) / k_{j}(t)$ by $(\mathrm{A} 15) \rightarrow w(t)=z(t) r_{\delta}(t) \rightarrow F_{j}(t)$ by the specified forms $\rightarrow p(t)$ by $(\mathrm{A} 9) \rightarrow \hat{y}(t)=p(t) F_{s}(t) / \gamma N \rightarrow c_{s}(t), c_{i}(t)$, and $s(t)$ by $(8) \rightarrow T_{p}(t)$ by $(14) \rightarrow K(t)=\bar{k}(t) N$ $\rightarrow Y_{p}(t)$ by $(10) \rightarrow a(t)=\bar{k}(t)+d(t)$.

The lemma implies that the motion of economic system at any point in time can be uniquely described as functions of the two variables, $\bar{k}(t)$ and $z(t)$. If we determine the motion of (18), it is straightforward to determine the motion of the whole system. As the expressions are too tedious, it is difficult to get explicit conclusions. For interpretation, we simulate the model. We specify parameter values as follows

$$
\begin{aligned}
& N=100, Y_{0}=3, A_{i}=1.1, A_{s}=0.9, A_{p}=0.9, \alpha_{i}=0.3, \alpha_{s}=0.35, \alpha_{0 p}=0.3, \beta_{0 p}=0.5, \\
& \lambda_{0}=0.7, \xi_{0}=0.15, \gamma_{0}=0.06, \theta_{p i}=0.07, \theta_{p s}=0.06, \tilde{\tau}_{s}=0.03, \tilde{\tau}_{i}=0.08, \tau_{k}=0.15, \\
& \tau_{w}=0.05, \tau_{i}=0.06, \tau_{s}=0.06, \delta_{k}=0.05 .
\end{aligned}
$$

The population is 100 . The government spends 3 on supplying public goods. The propensity to save is 0.7 . The propensity to consume goods is 0.15 , which is much higher than the propensity to consume services. The tax rates on consumption goods, service and interest income are respectively 8 percent, 3 percent, and 13 percent. The tax rates on the two sectors are 6 percent. It should be remarked that although the specified values are not based on empirical observations, the choice does not seem to be unrealistic. For instance, some empirical studies on the US economy demonstrate that the value of the parameter, $\alpha$, in the Cobb-Douglas production is approximately equal to 0.3. The depreciation rate of physical capital is fixed at 3 percent. Although the choice of the parameter values are not based on a special economy, this will not affect our main purpose of providing into interdependence between various variables by examining different changes in exogenous conditions such as policies and preferences on the economic dynamics. To simulate the model, we choose the initial conditions

$$
\bar{k}(0)=0.5, \quad z(0)=1 .
$$


We plot the motion of the dynamic system for a short period of time in Figure 1. The debt rises and the tax income falls over time. The labor employed by the public sector is increased but the capital is reduced. The price of service and wage rate rise over time. The rate of interest falls. The simulation demonstrates that the dynamic system does not approach to the equilibrium point. We will demonstrate that the equilibrium point is a saddle point. It is known that some neoclassical growth models with debts have saddle points (e.g., Turnovsky and Sen, 1991, Lin, 2000). For this kind of models, it is important to follow shifts of paths with changes in public policies and other parameters since the focus on unstable steady states does not provide enough information for behavior of the system. It should be noted that different policies for stabilizing government debts are suggested in the literature. For instance, according to Michel et al. (2010: 925), "To operationalize the notion of unstable government debt dynamics, we consider steady states which are locally unstable under the assumption of a permanently balanced primary budget. However, the economy can be stabilized at these steady states if one allows for appropriate budgetary adjustments. For tractability, we consider debt stabilizing rules that specify these adjustments as a linear function of the two state variables of the model (physical capital and real government debt). Moreover, we assume that such adjustments can be brought about by two different instruments (government consumption or a lump-sum tax on young agents)."
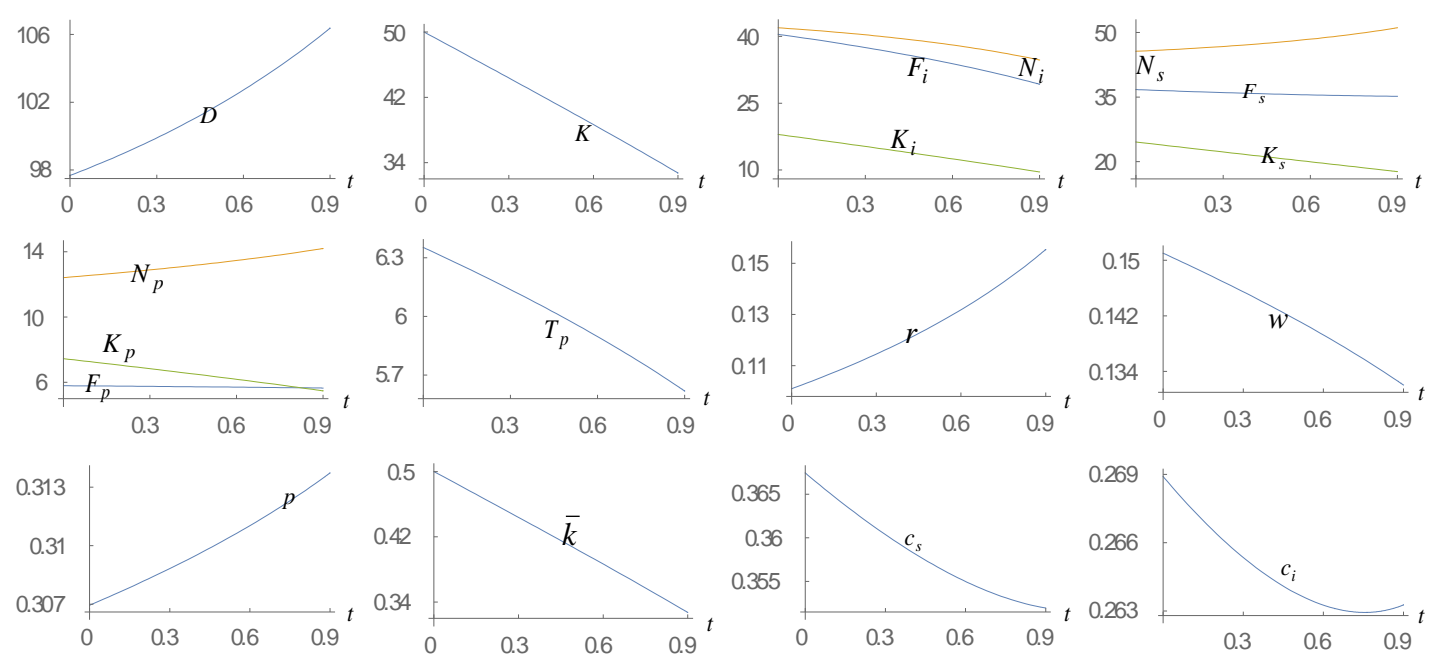

Figure 1. The Motion of the National Economy

We calculate the equilibrium values of the variables as follows

$$
\begin{aligned}
& D=26.29, T_{p}=5.91, r=0.11, p=0.31, w=0.15, N_{i}=63.05, N_{s}=24.19, N_{p}=12.76, \\
& K_{i}=24.72, K_{s}=11.92, K_{p}=7.00, F_{i}=59.20, F_{s}=18.88, F_{p}=5.76, k_{i}=0.39,
\end{aligned}
$$




$$
k_{s}=0.49, k_{p}=0.55, \bar{k}=0.44, c_{i}=0.14, c_{s}=0.19 \text {. }
$$

We see that the debt in Figure 1 is far from its equilibrium point and moves away from its equilibrium point. The eigenvalue at the equilibrium point are respectively 0.203 and -0.191 . The equilibrium point is a saddle point. It is straightforward to show that if we neglect taxation and debt in the model, the system has a stable unique equilibrium (Zhang, 2005). The introduction of dynamics of the public debt makes the neoclassical growth model unstable. It is well known that in traditional growth models with debt equilibria can be locally unique or indeterminate, depending on whether the government uses income taxes, consumption taxes or other policies (e.g., Judd, 1987; Turnovsky,1990; SchmittGrohe and Uribe, 1997; and Mankiw and Weinzierl, 2006).

\section{Comparative Dynamic Analysis}

The previous section plots the motion of the variables. As we have shown how to simulate the motion of the system, it is straightforward to make comparative dynamic analysis. As the equilibrium point is a saddle point, the system will not approach the equilibrium point except the initial condition is located on some special path. As Michel et al. (2010: 923) emphasize, "Unstable government debt dynamics can typically be stabilized around a certain target level of debt by appropriate budgetary adjustments. To achieve the needed budgetary corrections a government can normally adjust a broad range of fiscal instruments, like government spending, taxes or transfers. Yet, depending on the timing of actions and the particular instrument (or subset of instruments) that gets adjusted, successful stabilizations can be associated with a broad range of possible sequences of the budgetary balance during the adjustment period." The difficulty of describing possible dynamic adjustments is that one has to be follow dynamics under different exogenous changes. As our model can simulate the motion of the dynamic system, we can examine the dynamics of the whole system under any combination of fiscal policies and other parameters.

\section{A rise in the government's expenditure}

First, we examine the impact of the following change in the government's expenditure: $Y_{0}: 3 \Rightarrow 3.1$. We introduce a variable, $\bar{\Delta} x(t)$, to stand for the change rate of the variable, $x(t)$, in percentage due to changes in the parameter value. First, we examine the effects of the increase in the government expenditure on the equilibrium. The effects are listed in 
$\bar{\Delta} D=-2.19, \bar{\Delta} T_{p}=0.15, \bar{\Delta} r=-0.96, \bar{\Delta} p=-0.04, \bar{\Delta} w=0.54, \bar{\Delta} N_{i}=-0.35, \bar{\Delta} N_{s}=-0.55$, $\bar{\Delta} N_{p}=2.78, \bar{\Delta} K_{i}=0.85, \bar{\Delta} K_{s}=0.66, \bar{\Delta} K_{p}=4.02, \bar{\Delta} F_{i}=0.19, \bar{\Delta} F_{s}=0.03$,

$$
\bar{\Delta} F_{p}=2.59, \bar{\Delta} k_{i}=\bar{\Delta} k_{s}=\bar{\Delta} k_{p}=1.21, \bar{\Delta} \bar{k}=1.31, \bar{\Delta} c_{i}=-0.01, \bar{\Delta} c_{s}=0.03 \text {. }
$$

We see that as the expenditure is increased, the public sector enlarges its production scale, employing more labor and capital. As the public sector supplies more public goods, the productivities of the two production sectors are increased. Accordingly, the two sectors' output levels are reduced even though the labor inputs of the two sectors are reduced. The physical wealth is increased, which results in the increases of the capital stocks employed by all the sectors. The increased wealth is associated with the falling rate of interest and increasing wage rate. In association with the falling price of service, the consumption level of service is slightly increased. It should be noted that as the equilibrium point is a saddle point, in general one cannot guarantee that the system will approach its equilibrium. Hence, it is important to follow how the system moves when some exogenous change is added. Figure 2 plots how the system is affected over time. The public debt and tax income are reduced. Some of the labor force is shifted from the service sector to the goods sector and public sector. The total capital and the capital socks employed by the good and public sectors are increased, while the capital stock used by the service sector is reduced. The output levels of the public and goods sectors are increased, while that of the service sector is reduced. The wage rate and capital intensities rise. The rate of interest and the price of service rise initially but fall late on. The consumption levels of good and service are reduced. It should be remarked that the change directions of some variables in the equilibrium are not the same as those of the corresponding variables in the transitional processes. It should be noted that there are many studies concerning conditions for debt neutrality (Yaari, 1965; Blanchard, 1984, 1985; and Buiter, 1988). The model by Barro (1974) demonstrates the Ricardian equivalence hypothesis which implies that any mix of public debt and a lump-sum tax to finance government lump sum transfers has no real effect. It has been demonstrated that the debt neutrality is obtained from specified frameworks. In our approach as the government expenditure affects economic productivities a change in the government policy will affect the equilibrium of the economic system. 

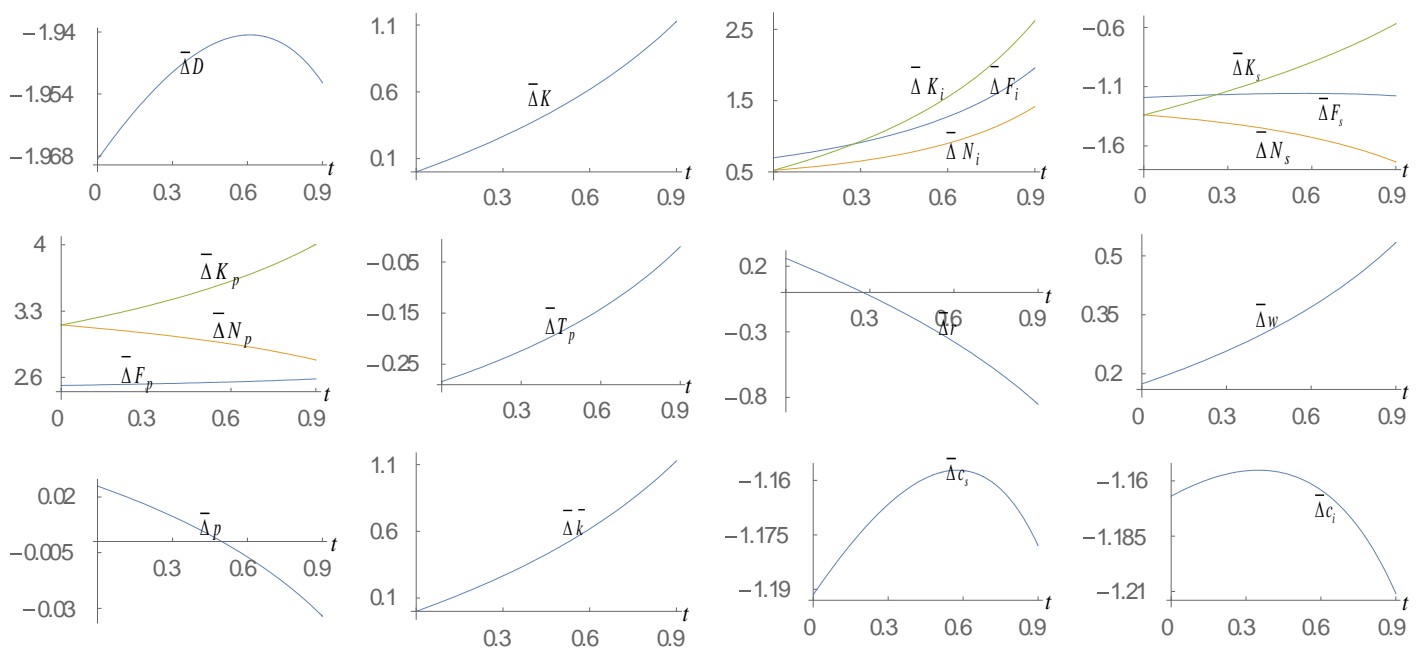

Figure 2. A Rise in the Government Expenditure

\section{A rise in the public sector's total productivity}

We now allow the total productivity of the public sector to be improved as follows: $A_{p}: 0.9 \Rightarrow 1$. The effects on the equilibrium are given in (22)

$$
\begin{aligned}
& \bar{\Delta} D=1.8, \bar{\Delta} T_{p}=1.04, \bar{\Delta} r=0.31, \bar{\Delta} p=0.07, \bar{\Delta} w=0.92, \bar{\Delta} N_{i}=0.12, \bar{\Delta} N_{s}=0.18, \\
& \bar{\Delta} N_{p}=-0.91, \bar{\Delta} K_{i}=0.82, \bar{\Delta} K_{s}=0.88, \bar{\Delta} K_{p}=-0.21, \bar{\Delta} F_{i}=1.03, \bar{\Delta} F_{s}=1.03, \\
& \bar{\Delta} F_{p}=10.54, \bar{\Delta} k_{i}=\bar{\Delta} k_{s}=\bar{\Delta} k_{p}=0.7, \bar{\Delta} \bar{k}=0.67, \bar{\Delta} c_{i}=1.09, \bar{\Delta} c_{s}=1.03 .
\end{aligned}
$$

As the productivity is improved, more public service is supplied by the public sector and less labor force and capital stocks are employed by the sector with the unchanged expenditure. As the productivities of the good and service sectors are increased, the output levels of the two sectors are increased. The rate of interest, the price of service, and wage rate are all increased. The wealth, the capital intensities, the consumption levels of good and service are all increased. Figure 3 plots how the system is affected over time. 

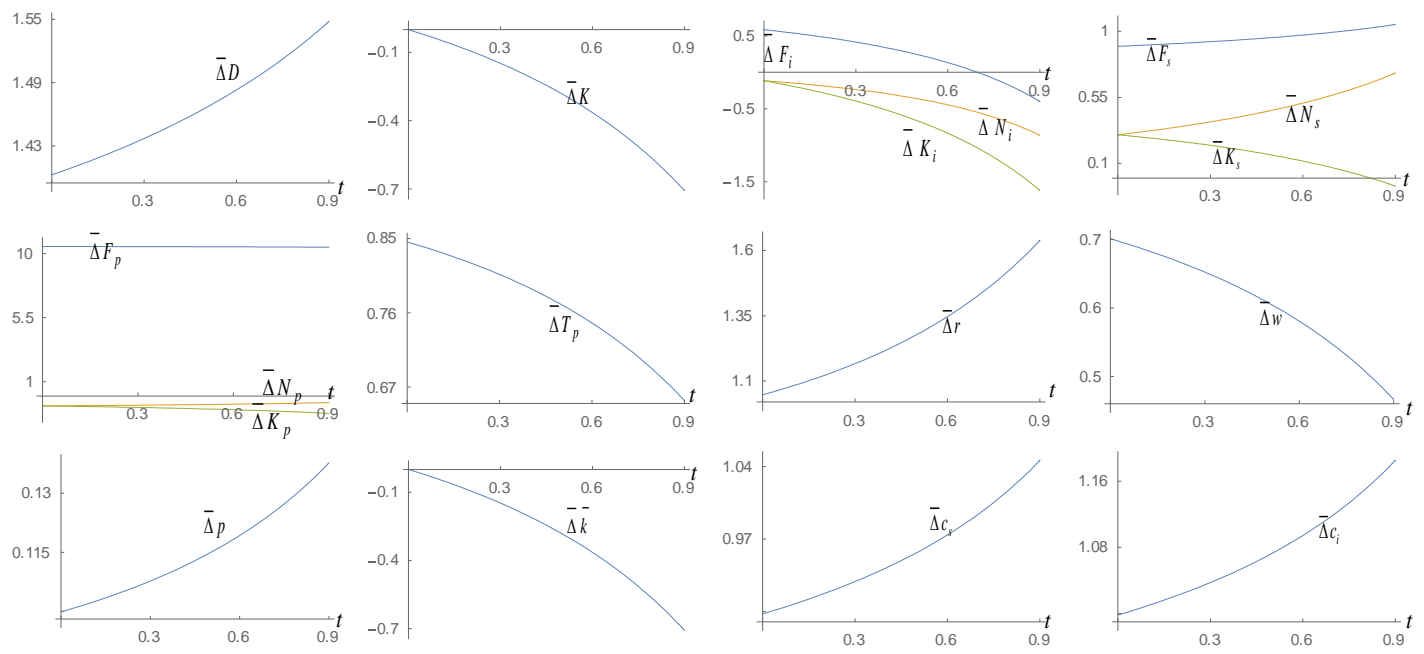

Figure 3. A Rise in the Total Productivity of the Public Sector

\section{A rise in the tax rate on the goods sector}

We now increase the tax rate on the goods sector as follows: $\tau_{i}: 0.06 \Rightarrow 0.08$. The effects on the equilibrium are given in (23)

$$
\begin{aligned}
& \bar{\Delta} D=17.7, \bar{\Delta} T_{p}=14.28, \bar{\Delta} r=9.59, \bar{\Delta} p=-1.52, \bar{\Delta} w=-5.56, \bar{\Delta} N_{i}=-3.39, \bar{\Delta} N_{s}=5.74, \\
& \bar{\Delta} N_{p}=5.89, \bar{\Delta} K_{i}=-14.42, \bar{\Delta} K_{s}=-6.32, \bar{\Delta} K_{p}=-6.2, \bar{\Delta} F_{i}=-6.78, \bar{\Delta} F_{s}=1.41, \\
& \bar{\Delta} F_{p}=0.95, \bar{\Delta} k_{i}=\bar{\Delta} k_{s}=\bar{\Delta} k_{p}=-11.41, \bar{\Delta} \bar{k}=-10.89, \bar{\Delta} c_{i}=-0.14, \bar{\Delta} c_{s}=1.41 .
\end{aligned}
$$

As the tax rate on the goods sector is increased, the total tax income is increased. As it has to pay more tax out of unit of its output, the goods sector reduces its output. As the good output is reduced, the rate of interest is increased. Some of the labor force is shifted from the goods sector to the public and service sectors. The wealth, the total capital and capital stocks employed by the three sectors are all reduced. As a consequence of the increase in the rate of interest and the fall in the goods sector, the debt is increased even though the expenditure is not changed and the tax income is increased. Figure 4 plots how the system is affected over time. 

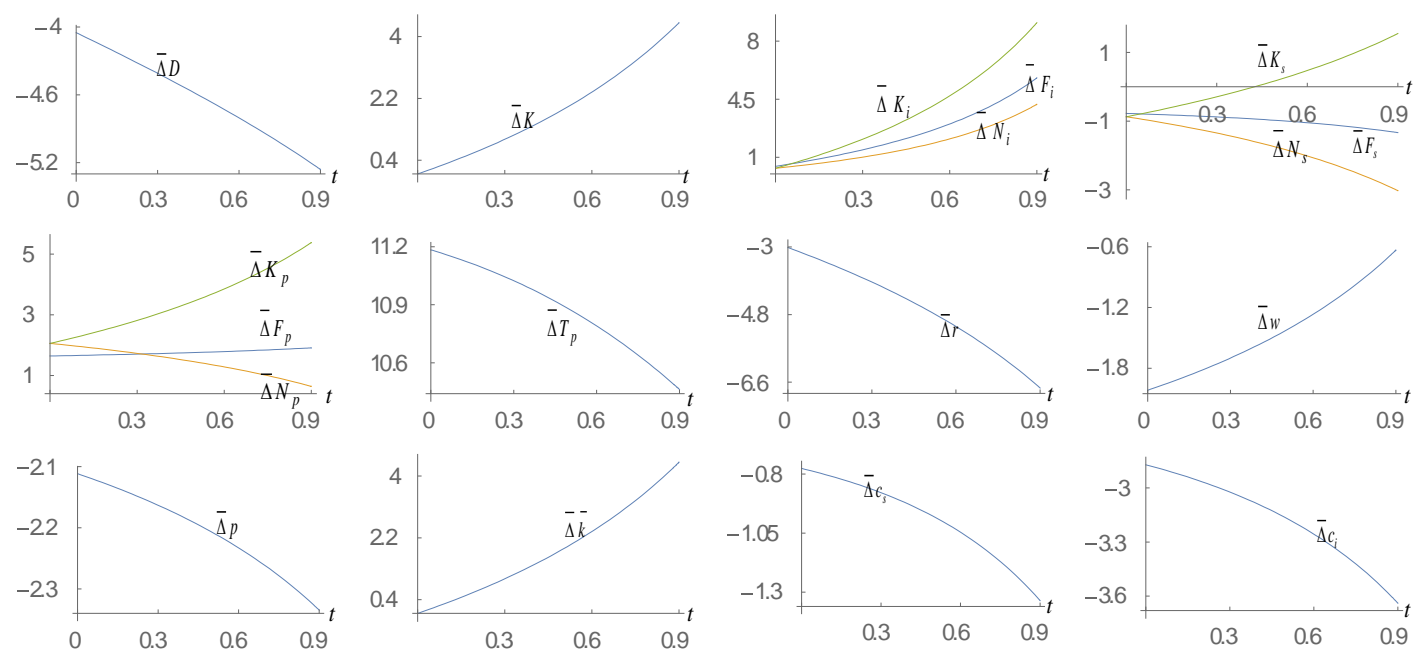

Figure 4. A Rise in the Tax Rate on the Goods sector

\section{Conclusions}

This paper developed a neoclassical two-sector economic growth model with public sector and debt in a competitive economy. The model describes nonlinear dynamic interactions among economic structural change, capital accumulation and public debt under different combinations of taxes on the goods sector, the service sector, the wage income, the interest return of wealth, consumption of good, and consumption of service. The model has a unique saddle equilibrium point. The study focuses on effects of changes in some policies on the equilibrium and transitional processes of the economic dynamics.

It should be remarked that the economic structures and interactions in our model are delicately interrelated. Our comparative dynamic analysis is limited to a few cases. We might get more insights from further simulation. It is possible to extend the model in some directions. The Solow model and the Uzawa two-sector growth model are most well-known models in the literature of growth theory. Many limitations of our model and possible extensions and generalizations become apparent in the light of the sophistication of the literature.

\section{Appendix: Proving Lemma 1}

From (2), (4) and (8), we get 


$$
z \equiv \frac{w}{r_{\delta}}=\bar{\alpha}_{i} k_{i}=\bar{\alpha}_{s} k_{s}=\bar{\alpha}_{p} k_{p}
$$

where $k_{p} \equiv K_{p} / N_{p}, \bar{\alpha}_{j} \equiv \beta_{j} / \alpha_{j}, j=i, s, p$. Insert $k_{j}=z / \bar{\alpha}_{j}$ and $N_{j}=K_{j} / k_{j}$ in (17)

$$
\bar{\alpha}_{i} K_{i}+\bar{\alpha}_{s} K_{s}+\bar{\alpha}_{p} K_{p}=z N
$$

From (A2) and $K_{i}=K-K_{s}-K_{p}$, we have

$$
\begin{aligned}
& K_{p}=\alpha_{x} N z-\alpha_{x} \bar{\alpha}_{i} K-\left(\bar{\alpha}_{s}-\bar{\alpha}_{i}\right) \alpha_{x} K_{s}, \\
& K_{i}=-N \alpha_{x} z+\alpha_{x} \bar{\alpha}_{p} K+\left(\bar{\alpha}_{s}-\bar{\alpha}_{p}\right) \alpha_{x} K_{s},
\end{aligned}
$$

where $\alpha_{x} \equiv 1 /\left(\bar{\alpha}_{p}-\bar{\alpha}_{i}\right)$. From (13) and (16), we have

$$
\gamma \hat{y} N=p F_{s}
$$

Substituting $r_{\delta}=\alpha_{s} \bar{\tau}_{s} p F_{s} / K_{s}$ into the above equation yields

$$
\gamma \hat{y} N=\frac{r_{\delta} K_{s}}{\alpha_{s} \bar{\tau}_{s}}
$$

From (10) and (11)

$$
\hat{y}=\left(1+\bar{\tau}_{k} r\right) \bar{k}+\bar{\tau}_{w} w+(1+r) d .
$$

Insert the above equation and $w=z r_{\delta}$ in (A4)

$$
\left(\delta_{0}+\bar{\tau}_{k} r_{\delta}\right) K+\bar{\tau}_{w} N z r_{\delta}+\left(\delta+r_{\delta}\right) D=\frac{r_{\delta} K_{s}}{\gamma \alpha_{s} \bar{\tau}_{s}},
$$


where we use $r=r_{\delta}-\delta_{k}, \delta_{0} \equiv 1-\bar{\tau}_{k} \delta_{k}$ and $\delta \equiv 1-\delta_{k}$. From (A6) we solve

$$
D=\left(\frac{r_{\delta} K_{s}}{\gamma \alpha_{s} \bar{\tau}_{s} N}-\delta_{0} \bar{k}-\bar{\tau}_{k} r_{\delta} \bar{k}-\bar{\tau}_{w} z r_{\delta}\right) \frac{N}{\delta+r_{\delta}} .
$$

From (6) and (8), we have

$$
K_{p}=\frac{\alpha_{p} Y_{0}}{r_{\delta}}
$$

From (A3) and (A8), we solve

$$
\begin{aligned}
& K_{s}=\left(\alpha_{x} N z-\alpha_{x} \bar{\alpha}_{i} N \bar{k}-\frac{\alpha_{p} Y_{0}}{r_{\delta}}\right) \frac{1}{\left(\bar{\alpha}_{s}-\bar{\alpha}_{i}\right) \alpha_{x}}, \\
& K_{i}=-N \alpha_{x} z+\alpha_{x} \bar{\alpha}_{p} K+\left(\bar{\alpha}_{s}-\bar{\alpha}_{p}\right) \alpha_{x} K_{s},
\end{aligned}
$$

From (2), we have

$$
r_{\delta}=\alpha_{i} \bar{\tau}_{i} A_{i} A_{p}^{\theta_{p i}} K_{p}^{\theta_{p i} \alpha_{0 p}} N_{p}^{\theta_{p i} \beta_{0 p}} k_{i}^{-\beta_{i}},
$$

where we also use (5). Insert $k_{i}=z / \bar{\alpha}_{i}$ and $N_{p}=\bar{\alpha}_{p} K_{p} / z$ in (A10)

$$
r_{\delta}=\alpha_{i} \bar{\tau}_{i} A_{i} A_{p}^{\theta_{p i}} K_{p}^{\theta_{p i} \alpha_{0 p}}\left(\frac{\bar{\alpha}_{p} K_{p}}{z}\right)^{\theta_{p i} \beta_{0 p}}\left(\frac{\bar{\alpha}_{i}}{z}\right)^{\beta_{i}} .
$$

Insert (A8) in (A10) 


$$
r_{\delta}=\Lambda(z) \equiv\left[\alpha_{i} \bar{\tau}_{i} A_{i} A_{p}^{\theta_{p i}}\left(\alpha_{p} Y_{0}\right)^{\theta_{p i}\left(\alpha_{0 p}+\beta_{0 p}\right)}\left(\frac{\bar{\alpha}_{p}}{z}\right)^{\theta_{p i} \beta_{0 p}}\left(\frac{\bar{\alpha}_{i}}{z}\right)^{\beta_{i}}\right]^{\theta_{\delta}}
$$

where $\theta_{\delta} \equiv 1 /\left[1+\theta_{p i}\left(\alpha_{0 p}+\beta_{0 p}\right)\right]$.

From (A12)-(A14) and (A16), we know that $r_{\delta}$ is a function of $z$. Insert (A16) and (A12) in $(A 7)$

$$
D=\Delta(z, \bar{k}) \equiv\left(\frac{\bar{\alpha}_{s} r_{\delta} K_{s}}{\gamma \alpha_{s} \bar{\tau}_{s} N z}-\delta_{0} \bar{k}-\bar{\tau}_{k} r_{\delta} \bar{k}-\bar{\tau}_{w} z r_{\delta}\right) \frac{N}{\delta+r_{\delta}} .
$$

By the following procedure we can determine all the variables as functions of $z$ and $\bar{k}: D$ by $(\mathrm{A} 12) \rightarrow r_{\delta}$ by $(\mathrm{A} 11) \rightarrow r=r_{\delta}-\delta_{k} \rightarrow K_{s}$ by $(\mathrm{A} 9) \rightarrow K_{i}$ by $(\mathrm{A} 9) \rightarrow K_{p}$ by $(\mathrm{A} 8) \rightarrow$ $k_{j}=z / \bar{\alpha}_{j}, j=i, s, p \rightarrow N_{j}=K_{j} / k_{j} \rightarrow K_{i}$ by $(\mathrm{A} 10) \rightarrow K_{s}$ by $(\mathrm{A} 6) \rightarrow N_{j}=K_{j} / k_{j}$, $j=i, s, p$ by $(\mathrm{A} 15) \rightarrow w=z r_{\delta} \rightarrow F_{j}$ by the specified forms $\rightarrow p$ by (A9) $\rightarrow$ $\hat{y}=p F_{s} / \gamma N \rightarrow c_{s}, c_{i}$ and $s$ by (13) $\rightarrow T_{p}$ by (15) $\rightarrow K=\bar{k} N \rightarrow Y_{p}=Y_{0} \rightarrow$ $a=\bar{k}+D / N$. By (9), (14) and this procedure, we have

$$
\begin{aligned}
& \dot{D}=\Psi(z, \bar{k}) \equiv r D+Y_{p}-T_{p}, \\
& \dot{\bar{k}}=\tilde{\Psi}(z, \bar{k}) \equiv s-\bar{k}-\frac{D}{N}-\frac{\Psi}{N} .
\end{aligned}
$$

Taking derivatives of $(\mathrm{A} 15)$ with respect to time yields

$$
\dot{D}=\frac{\partial \Delta}{\partial z} \dot{z}+\frac{\partial \Delta}{\partial \bar{k}} \dot{\bar{k}}
$$

From (A18) and (A20), we solve 


$$
\dot{z}=\hat{\Psi}(z, \bar{k}) \equiv\left(\Psi-\frac{\partial \Delta}{\partial \bar{k}} \tilde{\Psi}\right)\left(\frac{\partial \Delta}{\partial z}\right)^{-1},
$$

where we also use (A19). We thus proved Lemma 1.

\section{References}

Azariadis, C. (1993) Intertemporal Macroeconomics. MA., Cambridge: Blackwell.

Barro, R.J. (1974) Are Government Bonds Net Wealth? Journal of Political Economy 82, 1095-17.

Barro, R.J. (1990) Government Spending in a Simple Model of Endogenous Growth. Journal of Political Economy 98, S103-25.

Blanchard, O.J. (1983). Debt and Current Account Deficit in Brazil, in: Armella, P.A., Dornbusch, R., Obstfeld, M. (Eds.) Financial Policies and the World Capital Market: The Problem of Latin American Countries. Chicago: University of Chicago Press.

Blanchard, O. J. (1984) Current and Anticipated Deficits, Interest Rates and Economic Activity. European Economic Review 25, 7-27.

Blanchard, O. J. (1985) Debt, Deficits and Finite Horizons. Journal of Political Economy 93, 223-47.

Buiter, W.H. (1988) Death, Birth, Productivity Growth and Debt Neutrality. The Economic Journal 98, 279-93.

Burmeister, E. and Dobell, A.R. (1970) Mathematical Theories of Economic Growth. London: Collier Macmillan Publishers.

Diamond, P. (1965) National Debt in a Neoclassical Growth Model. American Economic Review 55, 1126-50.

Barro, R., Mankiw, N.G., Sala-i-Martin, X. (1995) Capital Mobility in Neoclassical Models of Growth. American Economic Review 85, 103-16.

Blanchard, O.J., Fischer, S., 1989. Lectures in Macroeconomics. MA., Cambridge: MIT Press.

Buiter, W.H. (1988) Death, Birth, Productivity Growth and Debt Neutrality. The Economic Journal 98, 279-93.

Chalk, N. (2000) The Sustainability of Bond-Financed Deficits: An Overlapping Generations Approach. Journal of Monetary Economics 45, 293-28.

Cohen, D., Sachs, J. (1986) Growth and External Debt under Risk of Debt Repudiation. European Economic Review 30, 529-60.

De la Croix, D. and Michel, P. (2002) A Theory of Economic Growth, Dynamics and Policy in Overlapping Generations. Cambridge: Cambridge University Press.

Diamond, P. (1965) National Debt in a Neoclassical Growth Model. American Economic Review 55, 1126-50.

Farmer, R. (1986) Deficits and Cycles. Journal of Economic Theory 40, 77-88. 
Frederick, S., Loewenstein, G., and O'Donoghue, T. (2002) Time Discontinuing and Time Preference: A Critical Review. Journal of Economic Literature 11, 317-36.

Giannitsarou, C. (2007) Balanced Budget Rules and Aggregate Instability: The Role of Consumption Taxes. Economic Journal 117, 1423-35.

Gómez, M.A. (2008) Fiscal Policy, Congestion, and Endogenous Growth. Journal of Public Economic Theory $10,595-622$

Guo, J., and Harrison, S. (2004) Balanced-Budget Rules and Macroeconomic (In)Stability. Journal of Economic Theory 119, 357-63.

Hochman, O. (1981) Land Rents, Optimal Taxation and Local Fiscal Independence in an Economy with Local Public Goods. Journal of Public Economics 15, 59-85.

Judd, K. (1987) A Dynamic Theory of Factor Taxation. American Economic Review 77, 42-48.

Lin, S.L. (2000) Government Debt and Economic Growth in an Overlapping Generations Model. Southern Economic Journal $66,754-63$.

Mankiw, G. and Weinzierl, M. (2006) Dynamic Scoring: A Back-of-the-Envelope Guide. Journal of Public Economics 90, 1415-33.

Michel, P., Thadden, L., and Vidal, J.P. (2010) Debt Stabilizing Fiscal Rules. Journal of Public Economic Theory 12, 923-41.

Park, H. (2009) Ramsey Fiscal Policy and Endogenous Growth. Economic Theory 39, 377-98.

Schmitt-Grohe, S., and Uribe, M. (1997) Balanced-Budget Rules, Distortionary Taxes and Aggregate Instability. Journal of Political Economy 105, 976-1000.

Semmler, W. and Sieveking, M. (2000) Critical Debt and Debt Dynamics. Journal of Economic Dynamics \& Control $24,1121-44$

Solow, R. (1956) A Contribution to the Theory of Growth. Quarterly Journal of Economics 70, 65-94.

Solow, R. M. (1962) Note on Uzawa's Two-Sector Model of Economic Growth. Review of Economic Studies 29, 48-50.

Swan, T.W. (1956) Economic Growth and Capital Accumulation. Economic Record 32, 334-61.

Turnovsky, S. (1990) The Effects of Taxes and Dividend Policy on Capital Accumulation and Macroeconomic Behavior. Journal of Economic Dynamics and Control 14, 491-521.

Turnovsky, S.J. (2000) Fiscal Policy, Elastic Labor Supply, and Endogenous Growth. Journal of Monetary Economics 45, 185-210.

Turnovsky, S.J. (2004) The Transitional Dynamics of Fiscal Policy: Long-Run Capital Accumulation and Growth. Journal of Money, Credit, and Banking 36, 883-910.

Turnovsky, B.J. and Sen, P. (1991) Fiscal Policy, Capital Accumulation, and Debt in an Open Economy. Oxford Economic Papers 43, 1-24. 
Uzawa, H. (1961) On a Two-Sector Model of Economic Growth. Review of Economic Studies 29, 47-70.

Wijkander, H. (1984) Provision of Public Goods in Congested Cities. Journal of Public Economics 25, 127-41.

Yaari, M. E. (1985) The Uncertain Lifetime, Life Insurance and the Theory of the Consumer. Review of Economic Studies 32, 137-50.

Zhang, W.B. (2005) Economic Growth Theory. London: Ashgate.

Zhang, W.B. (2008) International Trade Theory: Capital, Knowledge, Economic Structure, Money and Prices over Time and Space. Berlin: Springer.

Zhang, W.B. (2009) Agglomeration and Returns to Scale with Capital and Public Goods in a Multi-Regional Economy. International Economic Journal 23, 81-109.

Zhang, W.B. (2011) Economic Growth with Space and Fiscal Policies with Housing and Public Goods. Journal of Economic Studies 38, 452-82. 